ISSN = 1980-993X - doi:10.4136/1980-993X
www.agro.unitau.br/ambi-agua
E-mail: ambi-agua@agro.unitau.br
Tel.: (12) 3625-4116

\title{
Densidade fitoplanctônica e estado trófico dos rios Canha e Pariquera- Açu, bacia hidrográfica do rio Ribeira de Iguape, SP, Brasil
} (doi:10.4136/ambi-agua.55)

\author{
Davi Gasparini Fernandes Cunha'; Patrícia Bortoletto de Falco²; Maria do \\ Carmo Calijuri ${ }^{3}$ \\ ${ }^{1}$ Graduando em Engenharia Ambiental, Escola de Engenharia de São Carlos, Universidade de São Paulo \\ (EESC-USP). Av. Trabalhador São-Carlense, 400. CEP 13566-590. São Carlos, SP, Brasil \\ E-mail: davig@sc.usp.br \\ ${ }^{2}$ Pós-Doutora em Engenharia Hidráulica e Saneamento, Escola de Engenharia de São Carlos, Universidade \\ de São Paulo (EESC-USP) \\ ${ }^{3}$ Professora Titular, Escola de Engenharia de São Carlos, Universidade de São Paulo (EESC-USP)
}

\section{RESUMO}

Ao se considerar a carência de estudos a respeito do processo de eutrofização em sistemas lóticos, sobretudo em rios tropicais, esta pesquisa teve como objetivo principal comparar a comunidade fitoplanctônica dos rios Canha e Pariquera-Açu, (bacia hidrográfica do rio Ribeira de Iguape, SP), aos valores de IETm (Índice de Estado Trófico médio), em coletas realizadas em janeiro e abril de 2007. O IETm, originalmente concebido para ambientes lênticos, foi calculado com base nas concentrações de fósforo total, ortofosfato e clorofila- $a$ na água. A densidade da comunidade fitoplanctônica foi obtida a partir da contagem de indivíduos em câmaras de sedimentação. Comparando-se os valores do IETm aos resultados quantitativos do fitoplâncton, verificou-se que o IETm pode superestimar o estado trófico dos rios. Isso foi associado à contribuição das formas fosfatadas que compõem o cálculo do índice, as quais concorreram para o incremento indevido em seu valor, incompatível com a real resposta biológica associada, em relação à densidade fitoplanctônica. Em abril, apesar dos valores de IETm terem sido superiores, a densidade do fitoplâncton foi menor, com mínimo de $83 \mathrm{indmL}^{-1}$, no rio Canha, e de $66 \mathrm{indmL}^{-1}$, no rio Pariquera-Açu. Concluiu-se que, neste caso, as elevadas concentrações das formas fosfatadas não foram suficientes para promover proporcional crescimento fitoplanctônico, que deve ter sido limitado por outros fatores, tais como temperatura da água, concentração de sólidos em suspensão, vazão do rio e predação pelo zooplâncton. Em janeiro, por outro lado, embora o IETm tenha sido inferior, a densidade total do fitoplâncton foi maior. Nesta coleta, as menores concentrações de ortofosfato disponíveis na água indicaram a maior assimilação desse nutriente pelos microrganismos.

Palavras-chave: eutrofização de rios; comunidade fitoplanctônica; rios tropicais; Baixo Ribeira de Iguape (SP). 


\title{
Phytoplankton density and trophic state of Canha and Pariquera-Açu rivers, Ribeira de Iguape hydrographic basin, SP, Brazil
}

\begin{abstract}
Regarding the lack of studies about lotic eutrophication, mainly for tropical rivers, this research aimed to assess the density of phytoplanktonic community of two tropical rivers located in Ribeira do Iguape Watershed (São Paulo state, Brazil), Canha and Pariquera-Açu Rivers, based on sampling campaigns in January and April, 2007. These results were compared to the mTSI (mean Trophic State Index) values. This index was originally developed for lentic aquatic systems and its calculus depends on total phosphorous, orthophosphate and chlorophyll-a concentrations in water samples. Comparing mTSI values in all sampling stations with the phytoplankton quantitative results, it was possible to verify that mTSI may overestimate the trophic state of lotic ecosystems, since the phosphorus species that integrate its calculus contributed to an improper augmentation on mTSI, which were incompatible with the real associated biological response. Thus, for April sampling, although mTSI values were higher, in general, phytoplankton density were lower (minimum of $83 \mathrm{indmL}^{-1}$ for Canha River and of $66 \mathrm{indmL}^{-1}$ for Pariquera-Açu River). In this case, the high total phosphorous concentrations by themselves were not enough to promote proportional phytoplanktonic growth, which was probably limited by other factors, like water temperature, suspended solids concentration, river discharge and zooplanktonic predation. In January, on the other hand, mTSI values were lower, but total phytoplankton density was higher. For this sampling, the lower orthophosphate concentrations in water pointed phytoplankton assimilation of this nutrient.
\end{abstract}

Keywords: lotic eutrophication; phytoplanktonic community; tropical rivers; Ribeira do Iguape Valley (São Paulo state, Brazil).

\section{INTRODUÇÃO}

A avaliação do estado trófico de ecossistemas aquáticos pode ser adotada como instrumento de gestão dos recursos hídricos, uma vez que contribui para o entendimento da resposta biológica ao incremento de nutrientes, sobretudo fósforo e nitrogênio, nesses ambientes. Além disso, oferece subsídios para que sejam implementadas medidas de recuperação dos sistemas lênticos e lóticos, com base nos princípios da sustentabilidade e na manutenção dos usos múltiplos da água. Os organismos fitoplanctônicos são usualmente empregados em programas de monitoramento de eutrofização de ambientes aquáticos, pois são sensíveis às mudanças nas características físicas e químicas da água, sobretudo no que concerne à concentração de nutrientes. $O$ estudo desses organismos permite, ainda, acompanhar a evolução do grau de eutrofização do ecossistema e prevenir situações em que seja excedida a capacidade assimilativa do corpo receptor (Jarvie et al., 2002; Lobo et al., 2004; Potapova e Charles, 2005; Bellinger et al., 2006; Wang et al., 2007).

Historicamente, o fitoplâncton de ambientes lóticos tem recebido menos atenção em estudos limnológicos (Rodrigues et al., 2007). Características inerentes a esses sistemas, como a turbulência, o baixo tempo de residência da água e, conseqüentemente, o contínuo transporte da comunidade fitoplanctônica a jusante, levam a concluir, a princípio, que dificilmente haveria resposta biológica significativa ao incremento de nutrientes e que, portanto, a 
eutrofização nesses ambientes seria incomum. Entretanto, diversas pesquisas recentes têm demonstrado que o aporte de nutrientes aos ecossistemas lóticos pode ocasionar mudança drástica na biomassa, conduzindo à eutrofização (Dodds et al., 1998; Smith et al., 1999; Smith, 2003; Silveira, 2004; Dodds, 2006; Hilton et al., 2006; Billen et al., 2007).

Assim, o objetivo desta pesquisa foi comparar a densidade da comunidade fitoplanctônica aos valores do Índice de Estado Trófico médio (IETm) em dois rios tropicais sujeitos a diferentes magnitudes de impactos advindos de atividades antrópicas, os rios Canha e Pariquera-Açu. Para que esse objetivo fosse atingido, buscou-se relacionar algumas variáveis da água, tais como fósforo total, ortofosfato e clorofila-a, com a comunidade fitoplanctônica. Além disso, verificou-se a coerência da classificação de estado trófico de sistemas aquáticos, baseada nas concentrações de algumas formas fosfatadas e clorofila-a, com os resultados quantitativos do fitoplâncton. Analisou-se, também, a aplicabilidade dessa classificação para rios, já que foi desenvolvida, originalmente, para ecossistemas lênticos. Partiu-se da hipótese de que essa classificação, por ter sido concebida para lagos e reservatórios, poderia distorcer o real estado trófico de sistemas aquáticos lóticos.

Os rios Canha e Pariquera-Açu se situam na bacia hidrográfica do rio Ribeira de Iguape, porção sul do estado de São Paulo. As principais atividades econômicas desenvolvidas na subbacia do rio Jacupiranga, na qual se inserem os sistemas lóticos avaliados nesta pesquisa, são a agricultura (plantações de chá e banana) e pecuária (criação de búfalos, principalmente). No rio Pariquera-Açu, ocorre lançamento do efluente de uma lagoa de estabilização que trata o esgoto doméstico do município de mesmo nome. O rio Canha, por sua vez, não recebe despejos pontuais.

Vale destacar que o vale do rio Ribeira de Iguape apresenta significativos fragmentos remanescentes de Mata Atlântica, mais de 2,1 milhões de hectares de florestas, equivalente a aproximadamente $21 \%$ dos remanescentes de Mata Atlântica do país (Fundação SOS Mata Atlântica, 2001; Resende, 2002; Favareto e Brancher, 2005). Dessa forma, o estudo da comunidade fitoplanctônica e da concentração de nutrientes em sistemas aquáticos da região e, por conseguinte, a avaliação do potencial de eutrofização nesses ambientes, alvo desta pesquisa, pode contribuir para o desenvolvimento de planos de manejo dos recursos hídricos, que promovam a preservação do seu valioso patrimônio ambiental.

\section{MATERIAL E MÉTODOS}

Foram efetuadas duas coletas nos rios Canha e Pariquera-Açu, em janeiro e em abril de 2007. No rio Canha, as coletas ocorreram nos dias 17 de janeiro e 25 de abril de 2007 e, no rio Pariquera-Açu, nos dias 19 de janeiro e de 25 de abril de 2007. As estações amostrais foram selecionadas de forma a abranger locais considerados estratégicos (Tabela 1), por se localizarem nas proximidades das nascentes dos sistemas aquáticos, por sofrerem influência do meio urbano ou por receberem efluentes de ETE (Estação de Tratamento de Esgotos). Ao todo, foram determinadas oito estações no rio Canha e nove no rio Pariquera-Açu.

Para os rios Canha e Pariquera-Açu, a vazão foi calculada a partir da determinação das áreas de segmentos dos transectos e suas respectivas velocidades de escoamento. As velocidades de escoamento foram medidas com auxílio de molinete hidrométrico (medida de velocidade-área), de acordo com Wisler e Brater (1964). Os dados climatológicos foram obtidos de postos metereorológicos do IAC, Instituto Agronômico de Campinas (2007), localizados nos municípios de Jacupiranga e Pariquera-Açu.

Determinaram-se, também, as concentrações de fósforo total e fosfato inorgânico (ortofosfato), seguindo os protocolos descritos em APHA (2002), em amostras de água 
coletadas sub-superficialmente, além das concentrações de clorofila-a, utilizando etanol $80 \%$ para extração, de acordo com a metodologia de Nush (1980) modificada por NEN (1981). Todas as análises foram efetuadas com duas réplicas. A determinação da densidade total do fitoplâncton, por sua vez, foi feita a partir de amostras também coletadas subsuperficialmente, fixadas com lugol acético e quantificada pelo método da sedimentação (Uthermöhl, 1958).

Tabela 1. Referências de localização e coordenadas geográficas das estações de amostragem nos rios Canha e Pariquera-Açu.

\begin{tabular}{|c|c|c|c|c|}
\hline $\begin{array}{l}\text { Estação de } \\
\text { amostragem }\end{array}$ & \multicolumn{2}{|l|}{ Rio Canha } & \multicolumn{2}{|c|}{ Rio Pariquera-Açu } \\
\hline 1 & $\begin{array}{l}\text { Dossel fechado, sombreamento } \\
\text { do canal do rio }\end{array}$ & $\begin{array}{l}24^{\circ} 52^{\prime} 07^{\prime \prime} \mathrm{S} \\
47^{\circ} 57^{\prime} 55^{\prime}, \mathrm{W}\end{array}$ & Próximo à nascente & $\begin{array}{l}24^{\circ} 44^{\prime} 54^{\prime \prime} \mathrm{S} \\
47^{\circ} 56^{\prime} 58^{\prime \prime} \mathrm{W}\end{array}$ \\
\hline 2 & $\begin{array}{l}\text { Dossel menos denso e canal mais } \\
\text { largo que anterior }\end{array}$ & $\begin{array}{l}24^{\circ} 50^{\prime} 56^{\prime \prime} \mathrm{S} \\
47^{\circ} 57^{\prime} 55^{\prime \prime} \mathrm{W}\end{array}$ & Zona rural & $\begin{array}{l}24^{\circ} 43^{\prime} 46^{\prime \prime S} \\
47^{\circ} 56^{\prime} 28^{\prime \prime} \mathrm{W}\end{array}$ \\
\hline 3 & $\begin{array}{l}\text { Dossel menos denso e canal mais } \\
\text { largo que anterior }\end{array}$ & $\begin{array}{l}24^{\circ} 50^{\prime} 05^{\prime \prime} \mathrm{S} \\
47^{\circ} 57^{\prime} 37^{\prime}, \mathrm{W}\end{array}$ & $\begin{array}{l}\text { Antes do município de } \\
\text { Pariquera-Açu }\end{array}$ & $\begin{array}{l}24^{\circ} 43^{\prime} 36^{\prime \prime S} \\
47^{\circ} 54^{\prime} 26^{\prime \prime} \mathrm{W}\end{array}$ \\
\hline 4 & $\begin{array}{l}\text { Margens desmatadas } \\
\text { (bananicultura). Pequena faixa de } \\
\text { vegetação nas margens (< que } \\
\text { 30m). Sinais de assoreamento. }\end{array}$ & $\begin{array}{l}24^{\circ} 47^{\prime} 099^{\prime} \mathrm{S} \\
47^{\circ} 58^{\prime} 20^{\prime}, \mathrm{W}\end{array}$ & $\begin{array}{l}\text { Captação de água para } \\
\text { abastecimento público }\end{array}$ & $\begin{array}{l}24^{\circ} 43^{\prime} 00^{\prime \prime} \mathrm{S} \\
47^{\circ} 53^{\prime} 40^{\prime \prime} \mathrm{W}\end{array}$ \\
\hline 5 & Idem anterior & $\begin{array}{l}24^{\circ} 46^{\prime} 20^{\prime \prime} \mathrm{S} \\
47^{\circ} 58^{\prime} 54^{\prime}, \mathrm{W}\end{array}$ & $\begin{array}{l}\text { Antes do lançamento da } \\
\text { ETE }\end{array}$ & $\begin{array}{l}24^{\circ} 42^{\prime} 07^{\prime \prime S} \\
47^{\circ} 52^{\prime} 55^{\prime \prime} \mathrm{W}\end{array}$ \\
\hline 6 & Idem anterior & $\begin{array}{l}24^{\circ} 44^{\prime} 01^{\prime \prime} \mathrm{S} \\
47^{\circ} 59^{\prime} 36^{\prime}, \mathrm{W}\end{array}$ & $\begin{array}{l}\text { Depois do lançamento do } \\
\text { efluente da ETE }\end{array}$ & $\begin{array}{l}24^{\circ} 42^{\prime} 03^{\prime \prime} \mathrm{S} \\
47^{\circ} 52^{\prime} 55^{\prime \prime} \mathrm{W}\end{array}$ \\
\hline 7 & $\begin{array}{l}\text { Após passar pela periferia de } \\
\text { Jacupiranga (casas e escolas). } \\
\text { Margens desprotegidas e estação } \\
\text { localizada sob ponte na rodovia } \\
\text { SP } 222\end{array}$ & $\begin{array}{l}24^{\circ} 41^{\prime} 48^{\prime \prime}, \mathrm{S} \\
47^{\circ} 59^{\prime} 48^{\prime \prime} \mathrm{W}\end{array}$ & $\begin{array}{l}\text { Depois do município de } \\
\text { Pariquera-Açu }\end{array}$ & $\begin{array}{l}24^{\circ} 37^{\prime} 57^{\prime \prime} \mathrm{S} \\
47^{\circ} 50^{\prime} 59^{\prime \prime} \mathrm{W}\end{array}$ \\
\hline 8 & $\begin{array}{l}\text { Próxima à ETE de Jacupiranga. } \\
\text { Pequeno trecho de vegetação } \\
\text { seguida de pastagem }\end{array}$ & $\begin{array}{l}24^{\circ} 41^{\prime} 18^{\prime}, \mathrm{S} \\
47^{\circ} 59^{\prime} 44^{\prime \prime} \mathrm{W}\end{array}$ & $\begin{array}{l}\text { Próximo ao Parque Estadual } \\
\text { Campina do Encantado }\end{array}$ & $\begin{array}{l}24^{\circ} 36^{\prime} 41^{\prime \prime S} \\
47^{\circ} 46^{\prime} 38^{\prime \prime} \mathrm{W}\end{array}$ \\
\hline 9 & - & - & Foz do rio & $\begin{array}{l}24^{\circ} 37^{\prime} 56^{\prime \prime S} \\
47^{\circ} 44^{\prime} 12^{\prime \prime} \mathrm{W}\end{array}$ \\
\hline
\end{tabular}

Com base nas concentrações de fósforo total, ortofosfato e clorofila-a, o Índice de Estado Trófico médio (IETm) foi calculado de acordo com a Equação 1, proposta por Toledo et al. (1983).

$$
I E T m=\frac{I E T(P T)+I E T(P O 4)+I E T(C L)}{3}
$$

Em que:

$$
\operatorname{IET}(P T)=10\left[6-\frac{\ln (80,32 / P T)}{\ln 2}\right]
$$




$$
\begin{gathered}
\operatorname{IET}(P O 4)=10\left[6-\frac{\ln (21,67 / P O 4)}{\ln 2}\right] \\
\operatorname{IET}(C L)=10\left[6-\left(\frac{2,04-0,695 \ln (C L)}{\ln 2}\right)\right]
\end{gathered}
$$

PT: concentração de fósforo total $\left(\mu \mathrm{gL}^{-1}\right)$.

PO4: concentração de ortofosfato $\left(\mu \mathrm{gL}^{-1}\right)$.

$\mathrm{CL}$ : concentração de clorofila- $a\left(\mu \mathrm{gL}^{-1}\right)$.

$\ln$ : logaritmo natural.

Para a classificação do IETm, foram adotados os estados de trofia: ultraoligotrófico, oligotrófico, mesotrófico, eutrófico e hipereutrófico (Tabela 2).

Tabela 2. Classificação do estado trófico com base no resultado do cálculo do IETm.

\begin{tabular}{lc}
\hline Estado Trófico & Critério \\
\hline Ultraoligotrófico & IETm $\leq 24$ \\
Oligotrófico & $24<\mathrm{IETm} \leq 44$ \\
Mesotrófico & $44<\mathrm{IETm} \leq 54$ \\
Eutrófico & $54<\mathrm{IETm} \leq 74$ \\
Hipereutrófico & IETm $>74$ \\
\hline
\end{tabular}

Fonte: Toledo (1990).

No que se refere ao tratamento estatístico dos dados, as variáveis fósforo total, ortofosfato e clorofila-a dos dois rios foram submetidas à análise de cluster, por meio da qual foram obtidos dendogramas de similaridade entre as estações de amostragem. As análises estatísticas foram efetuadas no software Statistica 6.0.

\section{RESULTADOS E DISCUSSÃO}

Foram examinados dados de precipitação pluviométrica e de temperatura do ar do município de Jacupiranga (SP). Apesar de o rio Canha atravessar o município de Cajati, não havia disponibilidade de informações para essa localidade. Ressalta-se, contudo, que Jacupiranga é o município mais próximo de Cajati, distante cerca de $13 \mathrm{~km}$, que dispõe de informações meteorológicas. Os valores de chuva observados para janeiro e abril de 2007 foram, respectivamente, 301,0 e 91,0 $\mathrm{mm}$. Já a média das temperaturas mínimas e máximas nesses meses foram de 20,8 e $31,3^{\circ} \mathrm{C}$ (janeiro) e de 19,4 e $30,0^{\circ} \mathrm{C}$ (abril).

No município de Pariquera-Açu, atravessado pelo rio de mesmo nome, os valores de chuva observados para os meses de janeiro e abril de 2007 foram, respectivamente, 274,2 e 63,6 mm. A média das temperaturas máximas e mínimas para esses períodos foram de 30,3 e $20,5^{\circ} \mathrm{C}$ (janeiro) e de 29,1 e $19,4^{\circ} \mathrm{C}$ (abril).

Assim, as duas coletas abrangeram períodos que apresentaram padrões distintos de precipitação, sendo o mês de janeiro caracterizado como chuvoso e o mês de abril, como de estiagem. Os resultados das medições de vazão reforçaram essa constatação. Em janeiro, a vazão do rio Pariquera-Açu foi de $0,018 \mathrm{~m}^{3} \mathrm{~s}^{-1}, 0,137 \mathrm{~m}^{3} \mathrm{~s}^{-1}$ e $0,330 \mathrm{~m}^{3} \mathrm{~s}^{-1}$ nas Estações 1,3 e 5 , 
respectivamente. Já em abril, para as mesmas estações amostrais, as vazões calculadas foram de $0,015 \mathrm{~m}^{3} \mathrm{~s}^{-1}, 0,052 \mathrm{~m}^{3} \mathrm{~s}^{-1}$ e $0,247 \mathrm{~m}^{3} \mathrm{~s}^{-1}$. No que se refere ao rio Canha, as vazões medidas nas Estações 1, 4 e 8 foram, respectivamente, de $0,016 \mathrm{~m}^{3} \mathrm{~s}^{-1}, 0,705 \mathrm{~m}^{3} \mathrm{~s}^{-1}$ e $1,038 \mathrm{~m}^{3} \mathrm{~s}^{-1}$, na primeira coleta, e de $0,017 \mathrm{~m}^{3} \mathrm{~s}^{-1}, 0,500 \mathrm{~m}^{3} \mathrm{~s}^{-1}$ e $0,700 \mathrm{~m}^{3} \mathrm{~s}^{-1}$, na segunda.

A precipitação pluviométrica diária nas semanas em que houve campanhas amostrais nos rios Canha e Pariquera-Açu, além da variação da temperatura do ar em cada um dos dias, encontra-se na Tabela 3. Vale destacar que no dia da coleta em janeiro, no rio Canha, a precipitação foi de $10,0 \mathrm{~mm}$ e a temperatura do ar esteve entre 19,0 e $29,6^{\circ} \mathrm{C}$. Já para o rio Pariquera-Açu, não houve precipitação no dia da coleta de janeiro e as temperaturas do ar foram superiores, entre 22,0 e $33,7^{\circ} \mathrm{C}$. No que se refere à amostragem de abril, houve lâminas de chuva de 37,2 e 31,1 mm, nos rios Canha e Pariquera-Açu, respectivamente, durante os dias de coleta. Similarmente à coleta de janeiro, a temperatura do ar no município de Pariquera-Açu, no dia da coleta, foi superior à de Jacupiranga, atingindo valor máximo de $31,2^{\circ} \mathrm{C}$. Assim, apesar de abril ter sido considerado período de estiagem, em comparação com janeiro, houve lâminas de chuva relevantes durante os dias de coleta, em cada rio, nesse período.

Tabela 3. Precipitação pluviométrica $(\mathrm{mm})$ e variação da temperatura do ar $\left({ }^{\circ} \mathrm{C}\right)$ diárias nas semanas em que houve campanhas amostrais nos rios Canha e Pariquera-Açu.

\begin{tabular}{|c|c|c|c|c|}
\hline Município & Data & $\begin{array}{c}\text { Precipitação } \\
(\mathbf{m m})\end{array}$ & $\begin{array}{c}\text { Temperatura } \\
\text { mínima do ar }\left({ }^{\circ} \mathrm{C}\right)\end{array}$ & $\begin{array}{c}\text { Temperatura } \\
\text { máxima do ar }\left({ }^{\circ} \mathrm{C}\right) \\
\end{array}$ \\
\hline \multirow{12}{*}{ Jacupiranga } & $13 / 01 / 2007$ & 16,0 & 20,4 & 35,4 \\
\hline & $14 / 01 / 2007$ & 0,0 & 19,2 & 34,0 \\
\hline & $15 / 01 / 2007$ & 3,0 & 18,0 & 31,4 \\
\hline & $16 / 01 / 2007$ & 0,0 & 20,6 & 26,0 \\
\hline & 17/01/2007 (*) & 10,0 & 19,0 & 29,6 \\
\hline & Janeiro de 2007 & $301,0^{a}$ & $20,8^{b}$ & $31,3^{c}$ \\
\hline & $21 / 04 / 2007$ & 0,0 & 5,8 & 22,0 \\
\hline & $22 / 04 / 2007$ & 0,0 & 8,0 & 24,0 \\
\hline & 23/04/2007 & 27,9 & 10,2 & 20,0 \\
\hline & $24 / 04 / 2007$ & 30,4 & 15,0 & 17,0 \\
\hline & 25/04/2007 (*) & 37,2 & 13,8 & 24,2 \\
\hline & Abril de 2007 & $91,0^{a}$ & $19,4^{b}$ & $30,0^{c}$ \\
\hline \multirow{12}{*}{ Pariquera-Açu } & $15 / 01 / 2007$ & 0,0 & 19,4 & 30,8 \\
\hline & $16 / 01 / 2007$ & 0,0 & 18,8 & 27,2 \\
\hline & $17 / 01 / 2007$ & 0,0 & 18,4 & 29,8 \\
\hline & $18 / 01 / 2007$ & 19,0 & 19,2 & 32,0 \\
\hline & 19/01/2007 (*) & $\mathbf{0 , 0}$ & 22,0 & 33,7 \\
\hline & Janeiro de 2007 & $274,2^{a}$ & $20,5^{b}$ & $30,3^{c}$ \\
\hline & $21 / 04 / 2007$ & 0,0 & 19,0 & 30,8 \\
\hline & $22 / 04 / 2007$ & 0,0 & 19,6 & 29,2 \\
\hline & $23 / 04 / 2007$ & 0,0 & 20,0 & 31,4 \\
\hline & $24 / 04 / 2007$ & 0,0 & 20,0 & 34,0 \\
\hline & 25/04/2007 (*) & 31,1 & 20,6 & 31,2 \\
\hline & Abril de 2007 & $63,6^{a}$ & $19,4^{b}$ & $29,1^{c}$ \\
\hline
\end{tabular}

Legenda: $(*)$ dia em que houve coleta; ${ }^{a}$ total mensal; ${ }^{\mathrm{b}}$ Média das temperaturas mínimas verificadas em cada dia do mês; ${ }^{c}$ média das temperaturas máximas verificadas em cada dia do mês. Fonte: IAC (2007).

As concentrações de fósforo total na água do rio Canha variaram entre $5,0 \mu \mathrm{gL}^{-1}$ (Estação 1) e $28,4 \mu \mathrm{gL}^{-1}$ (Estação 7), em janeiro de 2007, e entre $13,1 \mu \mathrm{gL}^{-1}$ (Estação 4) e $36,8 \mu \mathrm{gL}^{-1}$ (Estação 6), em abril (Tabela 4). Para o rio Pariquera-Açu, essas concentrações foram 
maiores, oscilando, na primeira coleta, entre 33,3 $\mu \mathrm{gL}^{-1}$ (Estação 2) e 646,7 $\mu \mathrm{gL}^{-1}$ (Estação 9) e, na segunda, entre 20,7 $\mu \mathrm{gL}^{-1}$ (Estação 1) e 268,8 $\mu \mathrm{gL}^{-1}$ (Estações 6 e 9). Deve-se salientar que algumas concentrações verificadas no rio Pariquera-Açu estiveram em desacordo com o limite estabelecido pela Resolução CONAMA 357/05 (Brasil, 2005) para rios de classe 2, que é de 100,0 $\mu \mathrm{gL}^{-1}$. Nas Estações 5, 6, 7, 8 e 9, em janeiro e abril, e na Estação 4, em janeiro, concentrações superiores a esse valor foram observadas.

As concentrações dessa variável foram, em geral, superiores no rio Pariquera-Açu nas duas coletas, sobretudo à jusante da Estação 5, a partir da qual o sistema aquático sofre influência do município e do efluente da ETE. No caso da coleta de abril, em especial, deve-se considerar que houve rompimento da tubulação que veicula o efluente da ETE, o que pode ter contribuído para o incremento dessas concentrações já na própria Estação 5. Além disso, no que se refere à Estação 9, as elevadas concentrações de fósforo total foram associadas ao comportamento lêntico do rio nesse local, em função do encontro com o rio Ribeira de Iguape, o que proporciona desenvolvimento de macrófitas aquáticas. Sabe-se que as macrófitas que povoam os ambientes aquáticos podem contribuir significativamente para o aumento das concentrações de fósforo tanto na água como no sedimento (Demars e Harper, 1998; Bollmann et al., 2005; Lima et al., 2005; Xavier et al., 2005). Além disso, as baixas concentrações de oxigênio na água do rio Pariquera-Açu nessa estação podem ter promovido a liberação de fósforo previamente imobilizado no sedimento. Nas Estações 1, 2, 3, 4 e 9, as concentrações de fósforo total foram maiores em janeiro. Nas demais estações, as concentrações foram maiores em abril.

No caso do rio Canha, destaca-se a influência do município de Jacupiranga nas concentrações dessa variável na Estação 7, devendo-se levar em conta a contribuição de esgotos domésticos clandestinos, além de fontes difusas de poluição, já que essa estação se situa sob uma ponte na rodovia SP-222. As maiores concentrações de fósforo total foram observadas, majoritariamente, em abril de 2007. Deve-se reconhecer a importância do escoamento superficial no aumento das concentrações de fósforo total, principalmente, no rio Canha, já que as elevadas concentrações foram influenciadas, principalmente, pelas chuvas que ocorreram nos dias anteriores à coleta e, também, no próprio dia da amostragem de abril. Bordalo et al. (2001) relataram flutuações sazonais nas concentrações de fósforo total na água, sendo superiores no período de maior precipitação pluviométrica.

Uma vasta avaliação das concentrações de nutrientes em diversos rios do estado de São Paulo (Lamparelli, 2004), contudo, indicou que não há diferença estatisticamente significativa entre as concentrações de fósforo total na água encontradas nos períodos seco e chuvoso para 35 rios avaliados no estado. Segundo a mesma autora, embora as chuvas contribuam com o escoamento superficial e, conseqüentemente, para o incremento das concentrações de fósforo nos sistemas aquáticos, a precipitação pluviométrica também acarreta aumento do volume de água nos corpos de água e, por conseguinte, maior potencial de diluição de cargas poluidoras. No caso do rio Pariquera-Açu, parece ter havido equilíbrio entre esses dois fatores citados por Lamparelli (op. cit.), já que não houve padrão definido de variação sazonal nas concentrações de fósforo total.

O ortofosfato é a principal forma de fosfato assimilada por organismos aquáticos. Assim, a menor disponibilidade de ortofosfato em janeiro, para os dois rios, indicou maior assimilação pelo fitoplâncton. Tratando-se da variação espacial das concentrações de ortofosfato e clorofila-a, no rio Pariquera-Açu, destaca-se o incremento de fósforo a partir da Estação 5. Na Estação 6, houve picos de 7,00 e 11,16 $\mu \mathrm{gL}^{-1}$ de clorofila-a nas coletas de janeiro e abril, respectivamente, provavelmente como resultado do impacto do efluente da ETE. Na Estação 9, em função de seu comportamento lêntico, também foram observadas 
elevadas concentrações de ortofosfato nas duas amostragens. No caso do rio Canha, foram observadas menores concentrações de ortofosfato (máximo de 30,4 $\mu \mathrm{gL}^{-1}$, Estação 5, em abril) e de clorofila-a (máximo de 1,12 $\mu \mathrm{gL}^{-1}$, Estação 7, em abril, e Estação 8, em janeiro e abril).

A variação sazonal das concentrações de clorofila-a está vinculada a diversos fatores, tais como: maior atividade biológica, normalmente verificada nos meses de primavera e no verão, em que são observadas temperaturas mais elevadas; características hidráulicas (vazão do rio, velocidade da água), além de características da bacia hidrográfica em que se insere o sistema aquático estudado, cuja área pode ser ocupada, majoritariamente, por atividades agrícolas, industriais ou por meio urbano (Chai et al., 2006; Neal et al., 2006; Wysocki et al., 2006). Entretanto, para os rios Canha e Pariquera-Açu, não foi verificado padrão definido de variação sazonal das concentrações do pigmento.

Tabela 4. Concentrações de fósforo total, ortofosfato e clorofila-a $\left(\mu \mathrm{gL}^{-1}\right)$, nas estações de amostragem, nos rios Canha e Pariquera-Açu, em janeiro e abril de 2007.

\begin{tabular}{|c|c|c|c|c|c|c|c|}
\hline \multirow{2}{*}{ Rios } & \multirow{2}{*}{ Estação } & \multicolumn{2}{|c|}{ Fósforo total $\left(\mu \mathrm{gL}^{-1}\right)$} & \multicolumn{2}{|c|}{ Ortofosfato $\left(\mu \mathrm{gL}^{-1}\right)$} & \multicolumn{2}{|c|}{ Clorofila-a $\left(\mu \mathrm{gL}^{-1}\right)$} \\
\hline & & Janeiro & Abril & Janeiro & Abril & Janeiro & Abril \\
\hline \multirow{8}{*}{ Canha } & 1 & 5,0 & 26,3 & 4,3 & 10,6 & & 0,56 \\
\hline & 2 & 19,6 & 20,5 & 3,2 & 9,6 & b & b \\
\hline & 3 & 6,6 & 35,8 & 6,1 & 9,5 & 0,28 & b \\
\hline & 4 & 23,7 & 13,1 & 13,4 & 11,8 & 0,56 & 0,56 \\
\hline & 5 & 23,5 & 27,2 & 5,6 & 30,4 & $\mathrm{~b}$ & 0,56 \\
\hline & 6 & 9,0 & 36,8 & 6,8 & 14,5 & 0,56 & 0,84 \\
\hline & 7 & 28,4 & 32,8 & 11,3 & 23,2 & 0,84 & 1,12 \\
\hline & 8 & 10,6 & 31,9 & 17,7 & 19,9 & 1,12 & 1,12 \\
\hline \multirow{9}{*}{ Pariquera-Açu } & 1 & 62,7 & 20,7 & 27,8 & 18,0 & & 0,56 \\
\hline & 2 & 33,3 & 24,7 & 19,2 & 13,4 & b & 0,60 \\
\hline & 3 & 65,1 & 29,0 & 22,3 & 18,6 & b & 0,62 \\
\hline & 4 & $110,6^{\mathrm{a}}$ & 36,1 & 20,9 & 13,5 & 2,30 & 0,84 \\
\hline & 5 & $141,0^{\mathrm{a}}$ & $270,0^{\mathrm{a}}$ & 24,0 & 128,2 & 3,70 & 6,14 \\
\hline & 6 & $110,0^{\mathrm{a}}$ & $268,8^{\mathrm{a}}$ & 36,4 & 166,5 & 7,00 & 11,16 \\
\hline & 7 & $156,5^{\mathrm{a}}$ & $228,4^{\mathrm{a}}$ & 49,7 & 136,2 & 1,40 & 0,28 \\
\hline & 8 & $108,8^{\mathrm{a}}$ & $180,1^{\mathrm{a}}$ & 37,4 & 70,3 & 3,30 & 0,90 \\
\hline & 9 & $646,7^{\mathrm{a}}$ & $268,8^{\mathrm{a}}$ & 484,3 & 122,7 & 3,30 & 2,79 \\
\hline
\end{tabular}

Legenda: ${ }^{a}$ Concentração em desacordo com a Resolução CONAMA 357/05 (Brasil, 2005) para rios de classe 2;

${ }^{\mathrm{b}}$ Concentração de clorofila-a não detectada pelo espectrofotômetro.

Para o rio Canha, em janeiro, o menor IETm foi 19 (Estação 1) e o maior, 41, na Estação 7 (Tabela 5). Considerando a coleta de abril, os valores do IETm estiveram entre 30 (Estação 2) e 47 (Estação 7). Em janeiro, para o rio Pariquera-Açu, o IETm variou entre 35 (Estação 2) e 79 (Estação 9). Já em abril, oscilou entre 41 (Estações 1 e 2) e 74 (Estação 6). Para os dois sistemas lóticos estudados, o IETm das estações de amostragem foi, em geral, maior em abril.

É interessante notar que, em praticamente todos os casos, houve discrepância entre as classificações do IET (PT), IET (PO4) e IET (CL). Na maioria das estações amostrais, as formas fosfatadas classificaram o ambiente em classe superior à obtida pelo valor de clorofilaa, corroborando o que foi verificado por Lamparelli (2004), para rios do estado de São Paulo. Assim, o IETm pode ser superestimado em função das formas fosfatadas e nem sempre refletir o real estado de trofia do ambiente, no que se refere ao desenvolvimento de biomassa fitoplanctônica. No caso dos rios Canha e Pariquera-Açu, as concentrações de ortofosfato foram elevadas em abril, de modo geral, embora as concentrações de clorofila-a nesta coleta 
não as tenham acompanhado de forma consistente. Isso indicou menor assimilação da forma fosfatada pelo fitoplâncton, resultando em maiores concentrações disponíveis na água.

Tabela 5. Índice de Estado Trófico em relação ao fósforo total [IET (PT)], ao ortofosfato [IET (PO4)], à clorofila-a [IET $(\mathrm{CL})$ ] e Índice de Estado trófico médio (IETm), para as diferentes estações de amostragem nos rios Canha e Pariquera-Açu, em janeiro e abril de 2007.

\begin{tabular}{|c|c|c|c|c|c|c|c|}
\hline Rio & & Estação & IET (PT) & IET (PO4) & IET (CL) & IETm & Classificação \\
\hline \multirow{16}{*}{ Canha } & \multirow{8}{*}{$\begin{array}{c}\text { Janeiro } \\
\text { de } \\
2007\end{array}$} & 1 & $20(\mathrm{U})$ & $37(\mathrm{O})$ & $0(\mathrm{U})^{*}$ & 19 & ultraoligotrófico \\
\hline & & 2 & $40(\mathrm{O})$ & $32(\mathrm{O})$ & $0(\mathrm{U})^{*}$ & 24 & ultraoligotrófico \\
\hline & & 3 & $24(\mathrm{U})$ & $42(\mathrm{O})$ & $18(\mathrm{U})$ & 28 & oligotrófico \\
\hline & & 4 & $42(\mathrm{O})$ & $53(\mathrm{M})$ & $25(\mathrm{O})$ & 40 & oligotrófico \\
\hline & & 5 & $42(\mathrm{O})$ & $40(\mathrm{O})$ & $0(\mathrm{U})^{*}$ & 28 & oligotrófico \\
\hline & & 6 & $28(\mathrm{O})$ & $43(\mathrm{O})$ & $25(\mathrm{O})$ & 32 & oligotrófico \\
\hline & & 7 & $45(\mathrm{M})$ & $51(\mathrm{M})$ & $29(\mathrm{O})$ & 41 & oligotrófico \\
\hline & & 8 & $31(\mathrm{O})$ & $57(\mathrm{E})$ & $32(\mathrm{O})$ & 40 & oligotrófico \\
\hline & \multirow{8}{*}{$\begin{array}{c}\text { Abril } \\
\text { de } \\
2007\end{array}$} & 1 & $44(\mathrm{O})$ & $50(\mathrm{M})$ & $25(\mathrm{O})$ & 39 & oligotrófico \\
\hline & & 2 & $40(\mathrm{O})$ & $48(\mathrm{M})$ & $0(\mathrm{U})^{*}$ & 30 & oligotrófico \\
\hline & & 3 & $48(\mathrm{M})$ & $48(\mathrm{M})$ & $0(\mathrm{U})^{*}$ & 32 & oligotrófico \\
\hline & & 4 & $34(\mathrm{O})$ & $51(\mathrm{M})$ & $25(\mathrm{O})$ & 37 & oligotrófico \\
\hline & & 5 & $44(\mathrm{O})$ & $65(\mathrm{E})$ & $25(\mathrm{O})$ & 45 & mesotrófico \\
\hline & & 6 & 49 (M) & $54(\mathrm{M})$ & $29(\mathrm{O})$ & 44 & oligotrófico \\
\hline & & 7 & $47(\mathrm{M})$ & $61(\mathrm{E})$ & $32(\mathrm{O})$ & 47 & mesotrófico \\
\hline & & 8 & $47(\mathrm{M})$ & $59(\mathrm{E})$ & $32(\mathrm{O})$ & 46 & mesotrófico \\
\hline \multirow{18}{*}{ Pariquera-Açu } & \multirow{9}{*}{$\begin{array}{c}\text { Janeiro } \\
\text { de } \\
2007\end{array}$} & 1 & $56(\mathrm{E})$ & $64(\mathrm{E})$ & $0(\mathrm{U})^{*}$ & 40 & oligotrófico \\
\hline & & 2 & $47(\mathrm{M})$ & $58(\mathrm{E})$ & $0(\mathrm{U})^{*}$ & 35 & oligotrófico \\
\hline & & 3 & $57(\mathrm{E})$ & $60(\mathrm{E})$ & $0(\mathrm{U})^{*}$ & 39 & oligotrófico \\
\hline & & 4 & $65(\mathrm{E})$ & 59 (E) & $39(\mathrm{O})$ & 54 & mesotrófico \\
\hline & & 5 & $68(\mathrm{E})$ & $61(\mathrm{E})$ & $44(\mathrm{O})$ & 58 & eutrófico \\
\hline & & 6 & $65(\mathrm{E})$ & $67(\mathrm{E})$ & $50(\mathrm{M})$ & 61 & eutrófico \\
\hline & & 7 & $70(\mathrm{E})$ & $72(\mathrm{E})$ & $34(\mathrm{O})$ & 59 & eutrófico \\
\hline & & 8 & $64(\mathrm{E})$ & $68(\mathrm{E})$ & $43(\mathrm{O})$ & 58 & eutrófico \\
\hline & & 9 & $90(\mathrm{H})$ & $105(\mathrm{H})$ & $43(\mathrm{O})$ & 79 & hipereutrófico \\
\hline & \multirow{9}{*}{$\begin{array}{c}\text { Abril } \\
\text { de } \\
2007\end{array}$} & 1 & $40(\mathrm{O})$ & $57(\mathrm{E})$ & $25(\mathrm{O})$ & 41 & oligotrófico \\
\hline & & 2 & $43(\mathrm{O})$ & $53(\mathrm{M})$ & $25(\mathrm{O})$ & 41 & oligotrófico \\
\hline & & 3 & $45(\mathrm{E})$ & 58 (E) & $26(\mathrm{O})$ & 43 & oligotrófico \\
\hline & & 4 & 48 (E) & $53(\mathrm{M})$ & $29(\mathrm{O})$ & 43 & oligotrófico \\
\hline & & 5 & $77(\mathrm{H})$ & $86(\mathrm{H})$ & $49(\mathrm{M})$ & 71 & eutrófico \\
\hline & & 6 & $77(\mathrm{H})$ & $89(\mathrm{H})$ & $55(\mathrm{E})$ & 74 & eutrófico \\
\hline & & 7 & $75(\mathrm{H})$ & $87(\mathrm{H})$ & $18(\mathrm{U})$ & 60 & eutrófico \\
\hline & & 8 & 72 (E) & $77(\mathrm{H})$ & $30(\mathrm{O})$ & 59 & eutrófico \\
\hline & & 9 & $77(\mathrm{H})$ & $85(\mathrm{H})$ & $41(\mathrm{O})$ & 68 & eutrófico \\
\hline
\end{tabular}

Legenda: U (ultraoligotrófico); O (oligotrófico); M (mesotrófico); E (eutrófico); H (hipereutrófico); *Considerouse IET $(\mathrm{CL})=0$ para concentrações de clorofila-a não detectadas pelo espectrofotômetro.

Em janeiro de 2007, a densidade total do fitoplâncton no rio Canha variou entre 221 indmL $^{-1}$ (Estação 6) e 3.759 indmL $^{-1}$ (Estação 1) e, em abril, entre 83 indmL $^{-1}$ (Estação 8) e 752 indmL $^{-1}$ (Estação 1). Para o rio Pariquera-Açu, a densidade oscilou entre 129 indmL $^{-1}$ (Estação 3) e 1.769 indmL $^{-1}$ (Estação 6), na primeira coleta, e entre 66 indmL ${ }^{-1}$ (Estação 2) e 13.377 indmL $^{-1}$ (Estação 9), na segunda amostragem (Tabela 6). Estudo sobre o fitoplâncton da baía do Guajará e foz do rio Guamá, estado do Pará, Brasil, (Paiva et al., 2006) mostrou expressivo aumento do número de células por litro durante o período menos chuvoso, o que foi relacionado, pelos pesquisadores, à maior disponibilidade de luz e à maior transparência da água, favorecendo o florescimento fitoplanctônico. No caso dos rios Canha e Pariquera-Açu, 
situação semelhante foi observada, já que se verificou maior densidade de indivíduos no período que apresentou menor incidência de chuvas nos dias próximos de cada coleta, janeiro de 2007. Esse mês, apesar de ser caracterizado como chuvoso, em virtude do total mensal de precipitação, contou com pequenas lâminas de chuva no período específico de coleta, quando comparado a abril.

Tabela 6. Densidade total fitoplanctônica nas estações de amostragem nos rios Canha e Pariquera-Açu, em janeiro e abril de 2007.

\begin{tabular}{l|c|cc}
\hline \multirow{2}{*}{ Rios } & \multirow{2}{*}{ Estação } & \multicolumn{2}{|c}{ Densidade (indmL $^{-\mathbf{1}}$ ) } \\
\cline { 3 - 4 } Canha & 1 & 3.759 & Abril \\
\hline & 2 & 332 & 752 \\
& 3 & 663 & 111 \\
& 4 & 553 & 105 \\
& 5 & 265 & 133 \\
& 6 & 221 & 144 \\
& 7 & 409 & 205 \\
& 8 & 332 & 116 \\
& 1 & 290 & 83 \\
\hline \multirow{5}{*}{ Pariquera-Açu } & 2 & 143 & 94 \\
& 3 & 129 & 66 \\
& 4 & 567 & 105 \\
& 5 & 1.727 & 310 \\
& 6 & 1.769 & 1.121 \\
& 7 & 276 & 995 \\
& 8 & 543 & 111 \\
& 9 & 967 & 111 \\
& & & 13.377 \\
\hline
\end{tabular}

Para os dois rios, portanto, a densidade total do fitoplâncton foi, na maioria dos casos, maior em janeiro, embora o IETm tenha sido mais elevado em abril. Essa discordância confirmou a hipótese de que a avaliação do estado trófico por meio do IETm, originalmente desenvolvido para lagos e reservatórios, pode superestimar o grau de trofia dos rios. Isto ocorre, principalmente, em função das elevadas concentrações de fósforo encontradas em sistemas lóticos, as quais não promovem, necessariamente, resposta biológica diretamente proporcional a essas concentrações, isto é, aumento da densidade do fitoplâncton.

Portanto, embora o IETm tenha sido maior em abril, para os dois rios, as concentrações de fósforo total e ortofosfato verificadas nesta coleta não foram suficientes, por si só, para promover maior crescimento da comunidade fitoplanctônica, como seria esperado. Nesse caso, outros fatores podem ter interferido no desenvolvimento desses organismos, tais como a presença de sólidos em suspensão (e, conseqüentemente, a menor disponibilidade de luz), a predação pelo zooplâncton, entre outros. Em janeiro, por outro lado, embora os valores de IETm tenham sido menores, a densidade total do fitoplâncton foi maior, fato que, aliado às menores concentrações de ortofosfato disponíveis na água, indicou maior assimilação desse nutriente pelo fitoplâncton.

Os dendogramas de similaridade entre as estações de amostragem nos dois rios estudados estão sintetizados nas Figuras 1, 2, 3 e 4. 


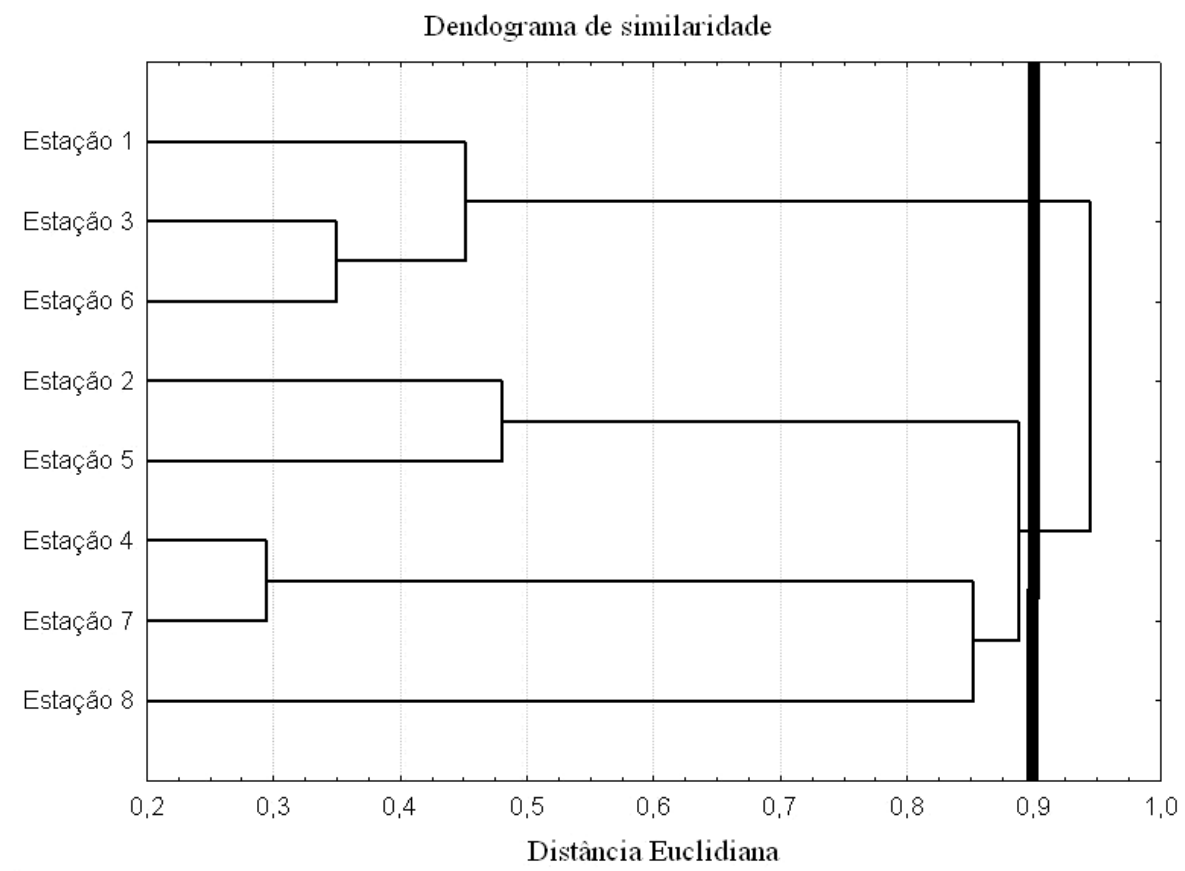

Figura 1. Dendograma da análise de agrupamento para fósforo total, ortofosfato e clorofila-a, entre as estações de amostragem do rio Canha, em janeiro de 2007.

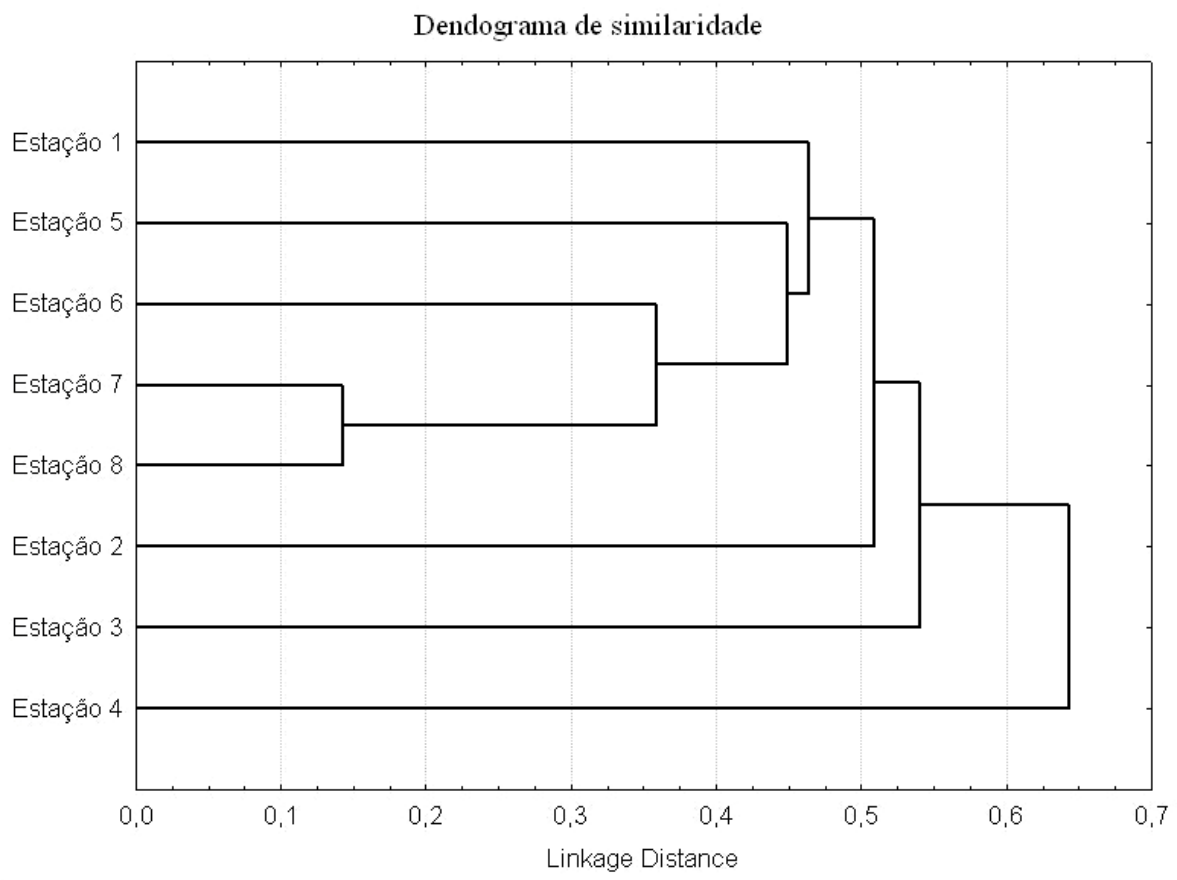

Figura 2. Dendograma da análise de agrupamento de fósforo total, ortofosfato e clorofila-a, entre as estações de amostragem, do rio Canha, em abril de 2007. 


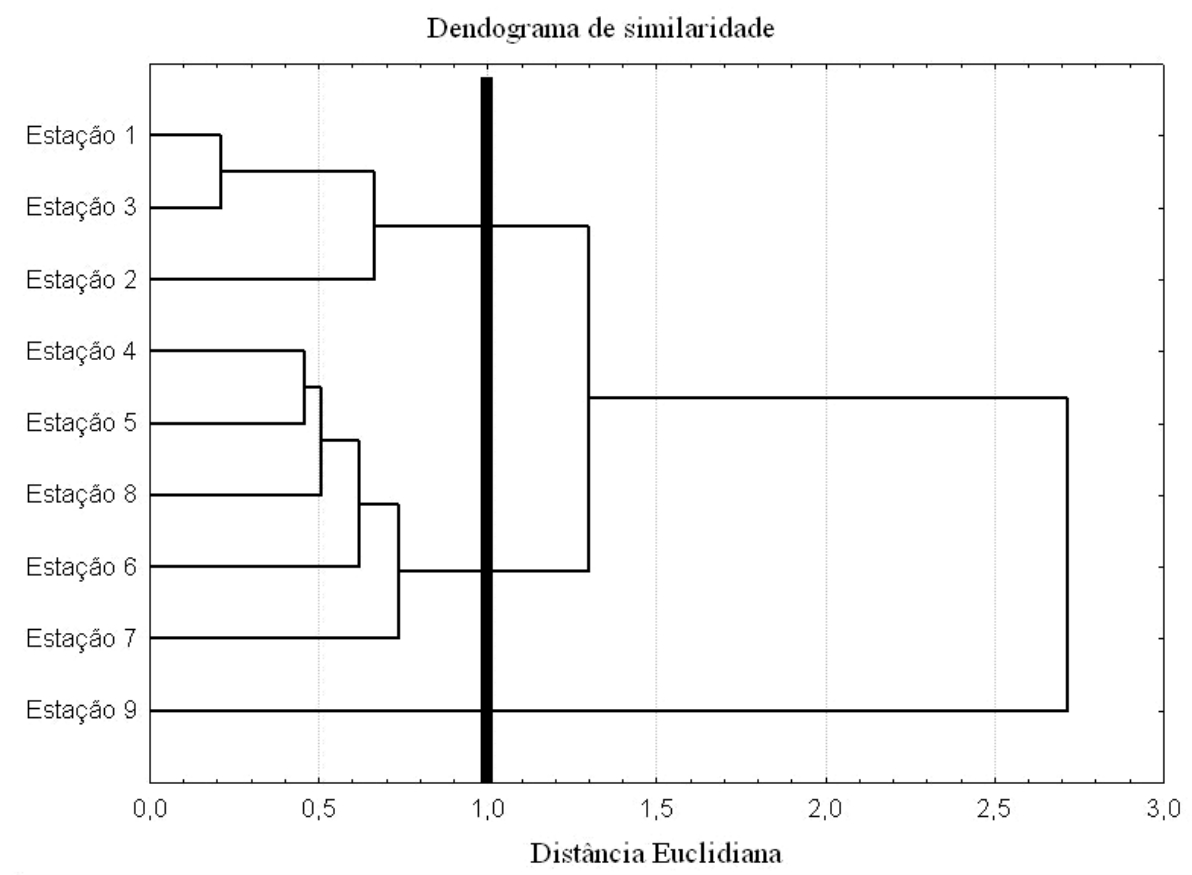

Figura 3. Dendograma da análise de agrupamento de fósforo total, ortofosfato e clorofila-a, entre as estações de amostragem, do rio PariqueraAçu, em janeiro de 2007.

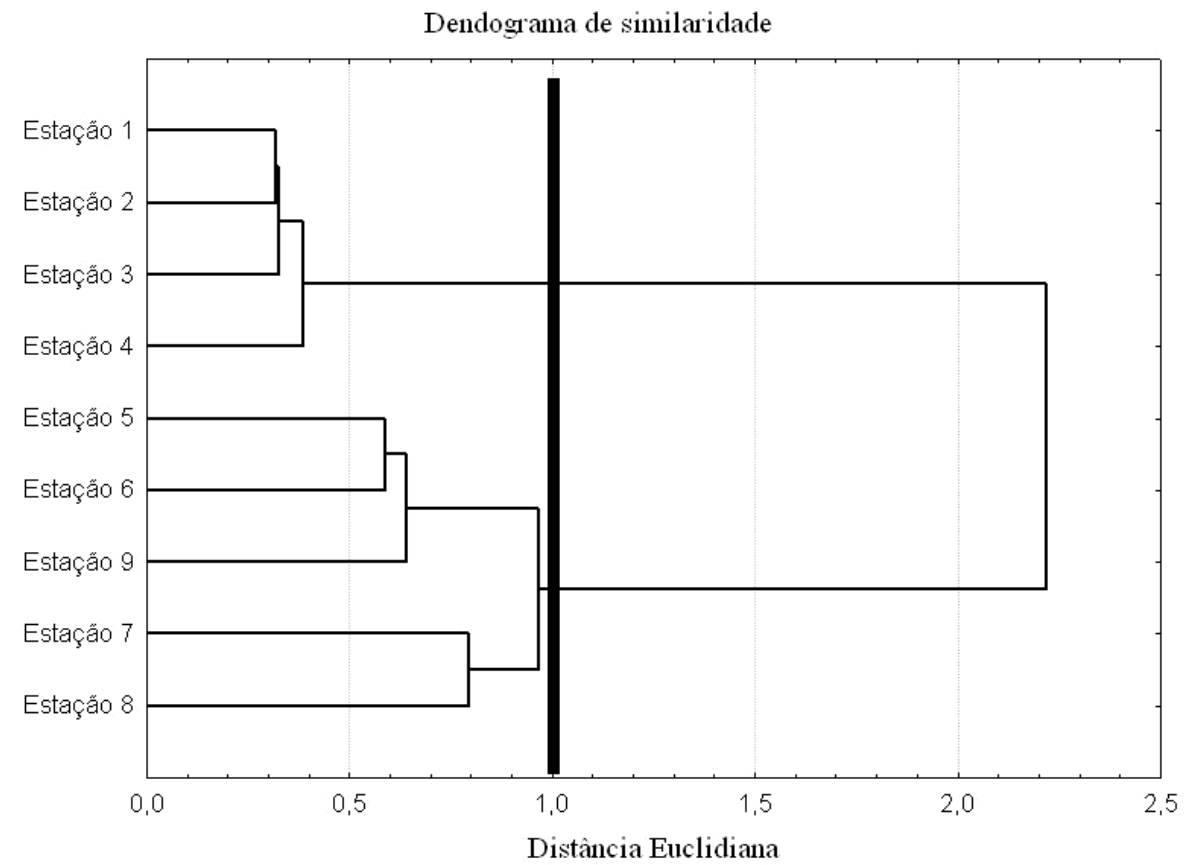

Figura 4. Dendograma da análise de agrupamento de fósforo total, ortofosfato e clorofila-a, entre as estações de amostragem, do rio Pariquera-Açu, em abril de 2007.

Para o rio Canha, considerando a coleta de janeiro de 2007, foram gerados dois grupos (distância euclidiana =0,9), um deles reunindo as Estações 1, 3 e 6, que apresentaram baixas concentrações de fósforo total, ortofosfato e clorofila- $a$ e o outro, agregando as demais estações. Para a coleta de abril, não foram gerados agrupamentos. A máxima distância euclidiana foi de aproximadamente 0,65, o que permitiu admitir que todas as estações de 
coleta apresentaram similaridade entre si, ou seja, que houve homogeneidade ao longo do eixo longitudinal do rio, considerando as variáveis fósforo total, ortofosfato e clorofila- $a$.

Para o rio Pariquera-Açu, na coleta de janeiro, foram gerados três agrupamentos (distância euclidiana $=1$ ).O primeiro grupo reuniu as Estações 1,2 e 3, próximas à nascente e trecho mais preservado do rio. O segundo agregou as Estações 4, 5, 6, 7 e 8, que já sofrem, em maior ou menor grau, os impactos do município de Pariquera-Açu, bem como aqueles relacionados ao efluente da ETE. Por fim, o terceiro grupo contou apenas com a Estação 9, que de fato apresenta características peculiares, em razão de seu comportamento lêntico, o que a distingue das demais. Já em abril, também considerando distância euclidiana igual a 1 , foram gerados dois agrupamentos: o primeiro conjunto reuniu as Estações 1, 2, 3 e 4; já o outro agregou as demais estações. Constata-se, portanto, que, em abril, a Estação 9 não foi alocada em grupo separado, mas sim no mesmo conjunto que encerrou as Estações 5, 6, 7 e 8. Isso pode ser explicado pelas elevadas concentrações de fósforo total e ortofosfato encontradas, em abril, a partir da Estação 5 (provavelmente em razão do rompimento da tubulação que veicula o efluente da ETE), o que pode ter contribuído para aumentar a similaridade entre as estações subseqüentes.

\section{CONCLUSÕES}

A comparação entre a densidade fitoplanctônica e o IETm dos rios Canha e PariqueraAçu, Vale do Ribeira de Iguape, SP, Brasil, em diferentes períodos amostrais (janeiro e abril de 2007) permitiu que fossem estabelecidas as seguintes conclusões:

i. De acordo com os resultados obtidos, não é aconselhável a aplicação do IETm (Índice de Estado Trófico médio), originalmente desenvolvido para ambientes lênticos, em estudos sobre sistemas lóticos, como os rios Canha e Pariquera-Açu, por exemplo. Pode haver superestimação do estado trófico do ecossistema aquático, já que as formas fosfatadas que integram o cálculo do IETm (fósforo total e ortofosfato) podem contribuir para um incremento indevido em seu valor, ou seja, um aumento incompatível com a real resposta biológica associada, representada pelo crescimento fitoplanctônico;

ii. A densidade total do fitoplâncton nos dois rios estudados, em diferentes períodos amostrais, confirmou a hipótese de superestimação do estado trófico pelo IETm. Em abril de 2007, embora os valores de IETm tenham sido maiores, a densidade total da comunidade fitoplanctônica foi menor, indicando que outros fatores intervieram na densidade desses organismos, tais como temperatura da água, concentração de sólidos em suspensão, vazão do rio, predação pelo zooplâncton, entre outros;

iii. As concentrações de fósforo e ortofosfato foram, em geral, maiores no rio Pariquera-Açu, em comparação às encontradas no rio Canha. Observou-se aumento dessas concentrações a partir da Estação 5 daquele rio, em função da influência do efluente da ETE, do município de Pariquera-Açu, do escoamento superficial urbano e rural e, ainda, do comportamento lêntico do rio em sua última estação de amostragem, o que propiciou desenvolvimento de macrófitas aquáticas. A análise de cluster reuniu de forma coerente as estações amostrais, de acordo com os impactos ambientais a que estiveram submetidas; 
iv. Não houve padrão definido de variação sazonal das concentrações de clorofila- $a$ na água dos dois rios estudados. Quanto ao fósforo total e ao ortofosfato, as maiores concentrações foram encontradas, no caso do rio Canha, em abril. Nessa ocasião, as chuvas que incidiram no período da coleta contribuíram para o aumento do escoamento superficial das áreas urbanas e agrícolas adjacentes e, conseqüentemente, para o aporte das formas fosfatadas ao rio. Por outro lado, no rio Pariquera-Açu não foi verificado padrão definido de variação sazonal dessas duas variáveis. Pressupõe-se que houve equilíbrio entre a entrada de fósforo no sistema lótico, em decorrência do escoamento superficial, e a diluição ocasionada pelo aumento do volume de água no rio, como resultado da precipitação pluviométrica.

\section{AGRADECIMENTOS}

Os autores agradecem à Fundação de Amparo à Pesquisa do Estado de São Paulo (FAPESP) pela bolsa de iniciação científica concedida ao primeiro autor (Processo FAPESP 06/53550-4), pela bolsa de pós-doutorado à segunda autora (Processo FAPESP 06/57668-0) e pelo auxílio financeiro (Processo FAPESP 02/13449-1).

\section{REFERÊNCIAS}

AMERICAN PUBLIC HEALTH ASSOCIATION - APHA. Standard methods for the examination of water and wastewater. 20. ed. Washington: APHA, 2002.

BELLINGER, B. J.; COCQUYT, C.; O'REILLY, C. M. Benthic diatoms as indicators of eutrophication in tropical streams. Hydrobiologia, v. 573, p. 75-87, 2006.

BILLEN, G.; GARNIER, J.; NÉMERY, J.; SEBILO, M.; SFERRATORE, A.; BARLES, S. et al. A long-term view of nutrient transfers through the Seine River continuum. The Science of the Total Environment, v. 375, p. 80-97, 2007.

BOLLMANN, H. A.; CARNEIRO, C.; PEGORINI, E. S. Qualidade da água e dinâmica de nutrientes. In: Gestão integrada de mananciais de abastecimento eutrofizados. Curitiba: Graf. Capital, 2005. 500 p.

BORDALO, A. A.; NILSUMRANCHIT, W.; CHALERMVAT, K. Water quality and uses of Bangpakong River, Eastern Thailand. Water Research, v. 35, p. 3635-3642, 2001.

BRASIL. Ministério do Meio ambiente. Conselho Nacional de Meio Ambiente - CONAMA. Resolução $\mathbf{n}^{0}$ 357, 17 de março de 2005. Disponível em: <http://www.mma.gov.br>. Acesso: 7 jul. 2007.

CHAI, C.; YU, Z.; SONG, X.; CAO, X. The status and characteristics of eutrophication in the Yangtze River (Changjiang) Estuary and the adjacent East China Sea. Hydrobiologia, v. 563, p. 313-328, 2006.

DEMARS, B. O. L.; HARPER, D. M. The aquatic macrophytes of an English lowland river system: assessing response to nutrient enrichment. Hydrobiologia, v. 384, p. 75-88, 1998 . 
DODDS, W. K.; JONES, J. R.; WELCH, E. B. Suggested classification of stream trophic state: distributions of temperate stream types by chlorophyll, total nitrogen and phosphorus. Water Research, v. 32, p. 1455-1462, 1998.

DODDS, W. K. Eutrophication and trophic state in rivers and streams. Limnology and Oceanography, v. 51, p. P. 671-680, 2006.

FAVARETO, A.; BRANCHER, P. O Desenvolvimento territorial no Vale do Ribeira e os projetos do Pronaf-infraestrutura - análise e recomendações. Relatório de Pesquisa. IICA-SDT/MDA. Disponível em: < http://serv-sdt-1.mda.gov.br/gnc/gnc/ep/estudos/SP _ValeRibeira.doc>. Acesso em: 10 fevereiro 2007.

FUNDAÇÃO SOS MATA ATLÂNTICA. Vale do rio Ribeira de Iguape. 2002. Disponível em: <http://www.sosmatatlantica.org.br>. Acesso: 10 fevereiro 2007.

HILTON, J.; O`HARE, M.; BOWES, M. J.; JONES, J. I. How green is my river? A new paradigm of eutrophication in rivers. Science of The Total Environment, v. 365, p. 6683, 2006.

INSTITUTO AGRONÔMICO DE CAMPINAS (IAC). Centro Integrado de Informações Agrometeorológicas - CIIAGRO. Balanço hídrico da região do Vale do Ribeira. Disponível em: <http://ciiagro.iac.sp.gov.br/ciiagroonline>. Acesso: 1 abril 2007.

JARVIE, H. P.; LYCETT, E.; NEAL, C.; LOVE, A. Patterns in nutrient concentrations and biological quality indices across the upper Thames river basin, UK. Science of the Total Environment, v. 283, p. 263-294, 2002.

LAMPARELli, M.C. Graus de trofia em corpos d'água do estado de São Paulo: Avaliação dos métodos de monitoramento. 2004. 235f. Tese (Doutorado em Ecossistemas Terrestres e Aquáticos) - Instituto de Biociências, Universidade de São Paulo (IB-USP), São Paulo, 2004.

LIMA, M. R.; REISSMANN, C. B.; TAFFAREL, A. D. Fitorremediação com macrófitas aquáticas flutuantes. In: Gestão integrada de mananciais de abastecimento eutrofizados. Curitiba: Graf. Capital, 2005. 500 p.

LOBO, E. A.; CALlEGARO, V. L. M.; HERMANY, G.; GÓMEZ, N.; ECTOR, L. Review of the use of microalgae in South America for monitoring rivers, with special reference to diatoms. Vie et Milieu-Life and Environment, v. 54, p. 105-114, 2004.

NEAL, C.; HILTON, J.; WADE, A. J.; NEAL, M.; WICKHAM, H. Chlorophyll-a in the rivers of eastern England. Science of the Total Environment, v. 365, p. 84-104, 2006.

NETHERLANDS NORMALISATIE INSTITUT - NEN. Nederlandse Norm 6520: water: spectrophotometric determination of chlorophyll a content. Delft: NEN, 1981.

NUSH, E. A. Comparison of different methods for chlorophyll and pheopigment determination. Arch. Hydrobiol., v. 14, p. 14-36, 1980.

PAIVA, R. S.; ESKINAZI-LEÇA, E.; PASSAVANTE, J. Z. O.; SILVA-CUNHA, M. G. C.; MELO, N. F. A. C. Considerações ecológicas sobre o fitoplâncton da baía do Guajará e foz do rio Guamá (Pará, Brasil). Ciências Naturais, v. 1, n. 2, p. 133-146, 2006. 
POTAPOVA, M.; CHARLES, D. F. Diatom metrics for monitoring eutrophication in rivers of the United States. Ecological Indicators, v. 7, p. 48-70, 2007.

RESENDE, R. U. As regras do jogo: legislação florestal e desenvolvimento sustentável no Vale do Ribeira. São Paulo: Annablume,2002. 198p.

RODRIGUES, S. C.; TORGAN, L.; SCHWARZBOLD, A. Composição e variação sazonal da riqueza do fitoplâncton na foz de rios do delta do Jacuí, RS, Brasil. Acta Botânica Brasilica, v. 21, p. 707-721, 2007.

SILVEIRA, M. P. Aplicação do biomonitoramento para avaliação da qualidade da água em rios. Jaguariúna: Embrapa Meio Ambiente, 2004. 68p.

SMITH, V. H.; TILMAN, G. D.; NEKOLA, G. D. Eutrophication: impacts of excess nutrient inputs on freshwater, marine, and terrestrial ecosystems. Environmental Pollution, v. 100, p. 179-196, 1999.

SMITH, V. H. Eutrophication of freshwater and coastal marine ecosystems: a global problem. Environmental Science \& Pollution Research, v. 10, p. 126-139, 2003.

TOLEDO, A. P.; TALARICO, M.; CHINEZ, S. J.; AGUDO, E. G. Aplicação de modelos simplificados para a avaliação de processo da eutrofização de lagos e reservatórios tropicais. In: CONGRESSO BRASILEIRO DE ENGENHARIA SANITÁRIA E AMBIENTAL, 22., 1983, Camburiú. Anais... Camburiú: UESC. 35p, 1983.

TOLEDO, A. P. Informe preliminar sobre os estudos para a obtenção de um índice para a avaliação do estado trófico de reservatórios de regiões quentes tropicais. São Paulo: CETESB, 1990. 12p. Relatório interno.

UTHERMÖHL, H. On the perfecting of quantitative phytoplankton method. Inst. Ass. Theor. Commum., v. 9, 1958.

XAVIER, C. F.; DIAS, L. N.; BRUNKOW, R. F. Eutrofização. In: Gestão integrada de mananciais de abastecimento eutrofizados. Curitiba: Graf. Capital, 2005. 500 p.

WANG, X. I.; LU, Y. I.; HE, G. Z.; HAN, J. Y.; WANG, T. Y. Exploration of relationships between phytoplankton biomass and related environment variables using multivariate statistic analysis in a eutrophic shallow lake: a 5-year study. Journal of Environmental Sciences, v. 19, p. 920-927, 2007.

WISLER, C. D.; BRATER, E. F. Hidrologia. Rio de Janeiro: Livro Técnico, 1964. 484 p.

WYSOCKI, L. A.; BIANCHI, T. S.; POWELL, R. T.; REUSS, N. Spatial variability in the coupling of organic carbon, nutrients, and phytoplankton pigments in surface waters and sediments of the Mississippi River plume. Estuarine, Coastal and Shelf Science, v. 69, p. 47-63, 2006. 